\title{
Constructing a Yield Curve in a Market with Low Liquidity
}

Sabit Khakimzhanov, National Bank of Kazakhstan s.khakimzhanov@nationalbank.kz

Yerulan Mustafin, National Bank of Kazakhstan yerulan.mustafin@nationalbank.kz

Olzhas Kubenbayev, National Bank of Kazakhstan olzhas.kubenbayev@nationalbank.kz

Dulat Atabek, Kolesa LLP

mendulatpin@gmail.com

Motivated by the shortcomings of the yield curve method used by the Kazakhstan Stock Exchange (KASE), we designed an algorithmic method of constructing a yield curve in a market with low and variable liquidity. We chose Nelson-Seigel as a curve and the ten most recent transactions in each subrange of maturity as the data. Both decisions stemmed from the constraints of an illiquid and inefficient market. The parsimony and rigidity of Nelson-Seigel proved useful when trades are few and prices are far apart. The choice of sampling is meant to produce enough sufficiently spaced observations, albeit at the expense of synchronicity. To provide the user better context for the curve and enable informed interpretation, we recommend supplementing the curves and their parameters with metrics of fit and age of the sample. Using the data from KASE, we computed the curve for each week starting from mid-2010 to end-2018 and made the results publicly available to provide access to interest rate data for analysts and to facilitate macroeconomic research.

Keywords: yield curve, Nelson-Siegel, Kazakhstan

Stock Exchange, algorithm, reproducible, market liquidity, zero-coupon, government bond

JEL Codes: $G 12$
Citation: Khakimzhanov, S., Mustafin, Y., Kubenbayev, O. and Atabek, D. (2019). Constructing a Yield Curve in a Market with Low Liquidity. Russian Journal of Money and Finance, 78(4), pp. 71-98.

doi: $10.31477 /$ rjmf.201904.71

\section{Introduction}

Regular construction and publication of a risk-free yield curve in a given currency support the effective functioning of a national financial market. A riskfree curve shows how the yield on risk-free debt depends on maturity. Constructed from government debt transactions data, it reflects and aggregates the willingness 
of the parties to save or to invest, their expectations about interest rates, and facilitates communication and price discovery in this market. By linking the short-term rates with the long-term rates, the curve represents a starting point of the monetary policy transmission mechanism. It acts as a benchmark for corporate debt and through corporate yield curves exerts its influence on other financial markets and the real sector, enabling decentralised coordination and planning of savings and investing activities in the entire economy.

In an illiquid and inefficient market constructing a curve poses a number of challenges and introduces trade-offs that are unfamiliar to a liquid and efficient market. For a start, there may be not enough market to represent. Low frequency of observations may require that transactions that are several days old should be included in the sample. Assumptions of efficiency that are implicit in a developed market may need to be tested and, possibly, revisited in a developing market.

This paper presents a yield curve methodology that responds to the challenges of Kazakhstan's risk-free market, applies it to Kazakhstan's data and publishes the curves on weekly basis for the period from 2010 to 2018. In Section 2, we characterize the data we use and the government debt market in Kazakhstan, its infrastructure, size, liquidity, and efficiency. We then discuss the requirements for curve modelling methodology in developed and less developed markets and introduce the canonical representations of the curve to build a conceptual toolbox for more concise discussion. This is combined with review of the literature on yield curve methodology with focus on the decisions and trade-offs that represent a variety of markets and objectives. In Section 4, we describe the methodology recently used by the Kazakhstan Stock Exchange (KASE) and also assess its compliance with the specified criteria. We proceed with a description of the proposed methodology and justifications of its decisions: the sampling method, the weighting scheme, the selection of parameters, and the communication format. In Section 6, we provide the optimisation algorithm and access to the source code, and provide examples of the curve. Discussion includes comparison with the approach used by KASE and with the approaches described in the literature. The paper concludes with discussion of the limitations of the proposed approach, how it could be improved upon and its contribution to our understanding of Kazakhstan's risk-free market and its development.

\section{Kazakhstan government debt market}

\subsection{Data}

The article used several types of data. To analyse the liquidity of the government securities market and to model the yield curve, we used the data from KASE-intermediated transactions and non-stock exchange transactions, in fixed income coupon bonds of the Ministry of Finance and discount notes of the National Bank of Kazakhstan (NBK) denominated in tenge (KZT). The data 
covers the period from 2010 to end 2018. The data includes the volume and prices of each transaction, coupon rates and payment dates on the underlying paper. The source is IRIS Finance, an information platform of the stock exchange, which provides data for a fee and restricts its distribution.

The data on the yield curve built by KASE was taken from the KASE website. The curve was presented as fitted price and yield to maturity for a list of securities in circulation at the end of the week from 2010 to end-2018. The data also includes the knot-points and the age of the sample for each maturity interval. The coefficients of the polynomials were not published by the stock exchange so we didn't use them in our analysis.

\subsection{Liquidity and efficiency of Kazakhstan government debt market}

The tenge-denominated government debt market of Kazakhstan has been inefficient and illiquid for a long time. Turnover in the secondary market, even in the best of times, was one-two orders of magnitude below the levels of countries with comparable income. The daily average trading volume in 2013 was $0.04 \%$ of the outstanding volume, 10 times less than in Russia and 100 times less than in Hungary. In 2014-2015, turnover declined by a factor of 10 and remained at that level for all long-term securities. At $0.02 \%$, the secondary market turnover in the short term is noted by NBK as extremely low as well, but much higher than in the long-term debt.

The main holders of long-term securities are pension and other public sector funds, commercial banks, and insurance companies. The share of brokers, other asset managers, individuals and non-residents is insignificant.

Figure 1. Tenge-denominated government debt in circulation

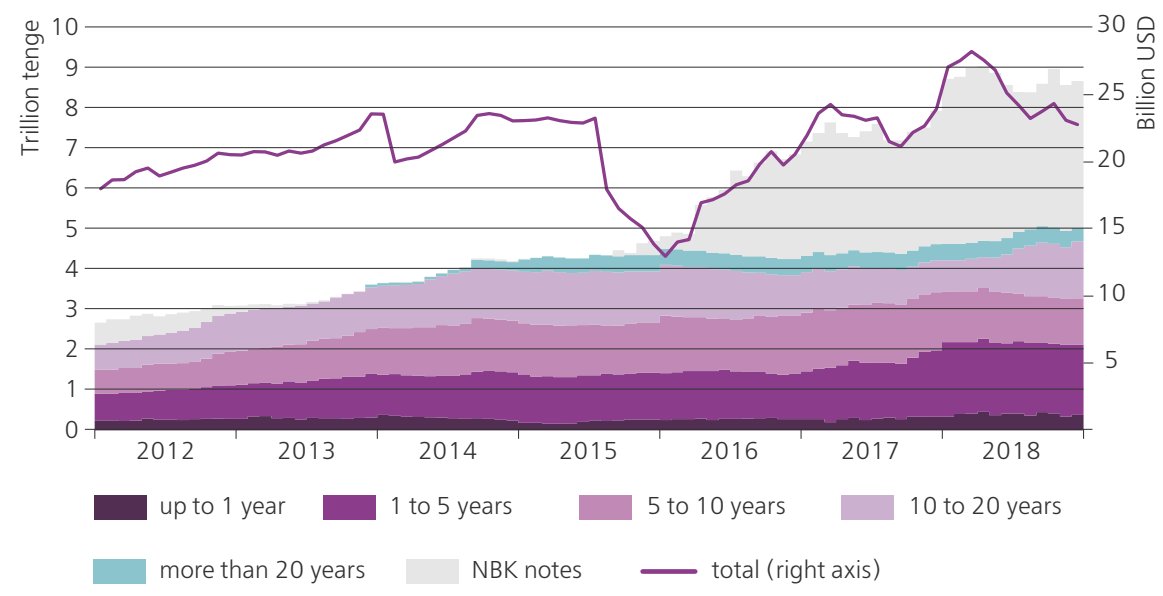

Source: Central Securities Depository 
All liquidity indicators are extremely low. Transactions are rare and executable quotes are not much more frequent. Even the largest and most liquid issues are not liquid enough to be used as benchmarks. They are traded only a few days per year. For some years, the number of days with two sided quotes is fewer than the number of days these issues are traded. Bid-ask spreads during 2011-2013 are on average 3.8-8.7 percentage points (p.p.) of the dirty price, or several orders of magnitude wider than 3 basis points (b.p) that the ECB sets as a threshold for benchmarks (Nymand-Andersen, 2018). Table 1a and 1b below provide some liquidity indicators for the most frequently traded issues. All other issues are much less liquid.

Table 1a. Liquidity metrics of the most frequently traded issues

\begin{tabular}{lcccccccc} 
& $\mathbf{2 0 1 1}$ & $\mathbf{2 0 1 2}$ & $\mathbf{2 0 1 3}$ & $\mathbf{2 0 1 4}$ & $\mathbf{2 0 1 5}$ & $\mathbf{2 0 1 6}$ & $\mathbf{2 0 1 7}$ & $\mathbf{2 0 1 8}$ \\
\hline Issue date, mm-yy & Aug-11 & Jul-11 & Apr-12 & Apr-12 & Apr-12 & Apr-12 & Apr-17 & Aug-14 \\
\hline Maturity date, mm-yy & Aug-26 & Jul-23 & Apr-32 & Apr-28 & Apr-32 & Apr-32 & Apr-21 & Aug-29 \\
\hline Coupon, $\%$ & 5.5 & 4.97 & 5.5 & 5 & 5.5 & 5.5 & 9.6 & 7.68 \\
\hline $\begin{array}{l}\text { Volume outstanding, bln } \\
\text { KZT }\end{array}$ & 51.0 & 30.7 & 37.7 & 78.0 & 37.7 & 37.7 & 114.0 & 156.6 \\
\hline Tenor, years & 15 & 11 & 19 & 14 & 17 & 16 & 4 & 11 \\
\hline \#days - trades & 16 & 47 & 27 & 18 & 8 & 4 & 5 & 17 \\
\hline \#days - asks & 26 & 32 & 48 & 38 & 18 & 5 & 14 & 30 \\
\hline \#days - bids & 27 & 49 & 25 & 20 & 8 & 3 & 6 & 21 \\
\hline \#days - quotes on 2 sides & 15 & 25 & 16 & 17 & 5 & 2 & 6 & 21 \\
\hline max bid-ask spread, p.p. & 5.2 & 18.5 & 23.1 & 0.8 & - & - & 0.9 & 4.8 \\
\hline min bid-ask spread, p.p. & 2.6 & 0.0 & 0.0 & 0.0 & - & - & 0.0 & 0.0 \\
\hline average bid-ask spread, p.p. & 3.8 & 7.8 & 8.8 & 0.3 & - & - & 0.3 & 1.2 \\
\hline
\end{tabular}

Note: ${ }^{*}$ number of days when limit orders on both sides were submitted.

Source: data - KASE, compilation - authors

Table $1 \mathrm{~b}$. Liquidity metrics of the second most frequently traded issues

\begin{tabular}{l|c|c|c|c|c|c|c|c} 
& $\mathbf{2 0 1 1}$ & $\mathbf{2 0 1 2}$ & $\mathbf{2 0 1 3}$ & $\mathbf{2 0 1 4}$ & $\mathbf{2 0 1 5}$ & $\mathbf{2 0 1 6}$ & $\mathbf{2 0 1 7}$ & $\mathbf{2 0 1 8}$ \\
\hline Issue date, mm-yy & Aug-09 & Oct-09 & Aug-12 & Apr-12 & Mar-11 & Dec-11 & Aug-09 & Aug-17 \\
\hline Maturity date, mm-yy & Aug-14 & Oct-16 & Aug-18 & Apr-32 & Mar-22 & Dec-21 & Aug-19 & Aug-21 \\
\hline Coupon, \% & 4.9 & 6 & 4.5 & 5.5 & 5.6 & 5.3 & 6 & 8.99 \\
\hline $\begin{array}{l}\text { Volume outstanding, bln } \\
\text { KZT }\end{array}$ & 12.2 & 14.5 & 25.7 & 37.7 & 41.3 & 28.2 & 38.7 & 137.1 \\
\hline Tenor, years & 3 & 4 & 5 & 18 & 7 & 5 & 2 & 3 \\
\hline \#days - trades & 14 & 16 & 11 & 27 & 3 & 2 & 7 & 3 \\
\hline \#days - asks & 35 & 37 & 38 & 37 & 19 & 2 & 8 & 6 \\
\hline \#days - bids & 19 & 22 & 16 & 30 & 2 & 2 & 16 & 4 \\
\hline \#days - quotes on 2 sides & 13 & 20 & 14 & 18 & 1 & 2 & 7 & 4 \\
\hline max bid-ask spread, p.p. & n/a & 5.4 & 4.4 & 10.5 & - & - & 0.9 & 0.8 \\
\hline min bid-ask spread, p.p. & n/a & 0.0 & 0.0 & 0.0 & - & - & 0.8 & 0.0 \\
\hline average bid-ask spread, p.p & n/a & 2.5 & 1.6 & 3.9 & - & - & 0.9 & 0.3 \\
\hline
\end{tabular}

Note: ${ }^{*}$ number of days when limit orders on both sides were submitted.

Source: data - KASE, compilation - authors 
Low liquidity in the primary market is a result of the government's low borrowing needs and the prevalence of captive investors.

Having emerged in the mid-1990s, Kazakhstan's government debt market grew rapidly after the fully-funded private pension system was established in 1998. Bank-like capital adequacy requirements imposed on pension equityconstrained asset managers generated demand for zero-weighted government debt from pension funds. Pension funds soon became the main holder of KZTdenominated government debt. In the 2000s, rising oil prices reduced borrowing needs and eventually produced a budget surplus. As a result, the real yields on government debt became negative. Voluntary investors stayed away from government debt, but demand from pension funds remained strong. By late 2013, half of pension assets was held in government debt while half of the outstanding government tenge-denominated debt was held by pension funds.

Captive demand distorted pricing in the primary market and suppressed liquidity in the secondary market. The gap between supply and voluntary demand widened during the episodes of elevated pressure on the exchange rate, regulatory tightening and transferring of pension into the Single Pension Fund.

Held-to-maturity accounting has also discouraged trading. A substantial part of Ministry of Finance bonds are classified by holders as held-to-maturity. In $2018,40 \%$ of government debt held by large banks was classified at amortised cost compared to $32 \%$ held-to-maturity in 2010 (see table below). Lax enforcement of restrictions on reclassifications allowed banks and institutional investors to reshuffle from a fair-value portfolio to a held-to-maturity portfolio in response to exchange rate pressure and the attendant rise in the yields.

Table 2. Classification of government securities according to IFRS (five largest holders among the banks)

\begin{tabular}{c|c|c} 
& Held-to-maturity, $\%$ & Available-for-sale, $\%$ \\
\hline 2010 & 32 & 41 \\
\hline 2014 & 10 & 71 \\
\hline 2018 & 40 & 60 \\
\hline
\end{tabular}

Note: in 2018 the number of banks decreased to four due to a merger.

Source: compiled by authors based on regulatory reporting data of NBK

Yet another factor of low liquidity and inefficiency was the threat of disciplinary action taken against the parties to a transaction that significantly deviated from the so-called 'market price', the fitted values computed from the KASE yield curve. This tended to inhibit the response of the market to fundamental shocks such as spikes in implied non-deliverable USD/KZT forward rates.

Inefficiency in the secondary market might have taken the form of a breach of fiduciary duty or fraud by asset managers who would buy high and sell low, diminishing the value of pension assets. In anonymised transaction data, such activity manifested itself as high yield variability. To counter such practices, 
pension funds were allowed to trade only on the stock exchange. This had little effect. The practice continued at the stock exchange well into late 2000s in the form of prearranged transactions between seemingly unrelated parties (transactions were timed to a second to avoid interception by other traders).

In 2011, KASE amended the rules for government securities trading. As soon as a bid and an ask met at a price that differed 'too much' from the KASE yield curve (KASE, 2003), continuous trading would stop and a time auction would start. This rule curtailed fraudulent trade by giving other traders time to intercept. Trading activity also decreased.

The inefficiency also manifested itself in the spread between the yields implied by the non-deliverable forwards and the yields on government debt. These widened whenever the pressure on the exchange rate would rise: in summer 2007, in winter 2008-2009, and in 2014-2015.

Consolidation of pension assets and their transfer to the management of the National Bank in 2014 led to further reduction of trading activity, both primary and secondary.

In addition, liquidity has been hampered by having too many issues in circulation, too small to be held by several investors. In 2013, there were about 120 Ministry of Finance issues, each, on average, KZT 19 billion in volume (USD 120 million) (Table 3). By 2019, the average issue size increased but was still under the USD 1 billion threshold compared to the Russian government debt market in 2013 with 23 issues, on average USD 3.7 billion each.

Table 3. Outstanding government debt structure

\begin{tabular}{c|c|c|c|c|c|c|c|c|c|}
\hline & \multicolumn{3}{|c|}{ Russia 2013 } & \multicolumn{3}{c|}{ Kazakhstan 2013 } & \multicolumn{3}{c|}{ Kazakhstan Nov 2019 } \\
\hline $\begin{array}{c}\text { Years to } \\
\text { maturity }\end{array}$ & $\begin{array}{c}\text { Issues in } \\
\text { circulation }\end{array}$ & $\begin{array}{c}\text { Volume, } \\
\text { USD bln }\end{array}$ & $\begin{array}{c}\text { Average } \\
\text { size, } \\
\text { USD bln }\end{array}$ & $\begin{array}{c}\text { Issues in } \\
\text { circulation }\end{array}$ & $\begin{array}{c}\text { Volume, } \\
\text { USD bln }\end{array}$ & $\begin{array}{c}\text { Average } \\
\text { size, } \\
\text { USD bln }\end{array}$ & $\begin{array}{c}\text { Issues in } \\
\text { circulation }\end{array}$ & $\begin{array}{c}\text { Volume, } \\
\text { USD bln }\end{array}$ & $\begin{array}{c}\text { Average } \\
\text { size, } \\
\text { USD bln }\end{array}$ \\
\hline$<=1$ & 4 & 9.4 & 2.4 & 22 & 1.8 & 0.08 & 12 & 0.6 & 0.05 \\
\hline $1-5$ & 9 & 36.6 & 4.2 & 51 & 5.8 & 0.11 & 31 & 4.3 & 0.14 \\
\hline $5+$ & 10 & 36.1 & 3.6 & 48 & 6.5 & 0.14 & 36 & 9.8 & 0.27 \\
\hline Total & 23 & 82.1 & 3.7 & 121 & 14.1 & 0.12 & 79 & 14.7 & 0.19 \\
\hline
\end{tabular}

Source: Ministry of Finance, Central Depository

In 2015, the National Bank let tenge float and began to manage short-term interest rates in 2016. The turbulence in the intermediate period led to an increase in short-term interest rates (Figure 11).

In 2016-2017, a large budget deficit and massive dedollarisation of bank liabilities led to an expansion of the National Bank balance sheet and the corresponding expansion of the banking system's liquid assets. The National Bank absorbed excess base money by using short-term notes (Figure 1). The notes quickly became the most liquid form of government debt. The short-term end of the curve started to be updated much more frequently. Trading in Ministry of Finance issues has remained rare. 


\section{Methodology requirements, types of yield curves and approximating functions}

The development of yield curve methodology involves choosing the shape of the curve, and the method of aggregation of transactions and approaches to ensure the internal consistency of the curve. The process needs to be reproducible, transparent, decisions need to be justified objectively, explicitly documented, and access to source code should be provided.

Designing of a yield curve methodology is driven by its purpose and the constraints of the market and the data. A liquid market is effective and selfsufficient. In a liquid market, a user may want to track the state of the market as accurately and closely as possible. For example, a trader may need a curve to detect a mispriced quote and to trade it. A curve built for this purpose needs to be flexible enough to reflect the consensus of the market, but not too flexible in order to enable detection of the mispriced quote. The sample would need to be as close to real time as possible: the curve should reflect executable quotes rather than past transactions.

At the other end of the liquidity spectrum are the markets where observations are infrequent. With only a few observations in the sample, the constraints imposed on the shape of the curve may improve its stability. Restricting the sample to a point in time, say, '17:00 or immediately before it', would result in a sample with missing data.

For example, in Kazakhstan during 2014-2016 the 'dry' days when no single government security was traded, were more common than the days with at least one trade; 'dry' weeks can be found in every quarter; 'dry' spans lasting three weeks happened every year and there was one that lasted five weeks. In such periods, a sample may need to be an asynchronous one and include observations that are days or months old. The choice of such a sample would be justified in a static market, too slow to change between the oldest and the youngest observation. However, if the curve changed during that time, an asynchronous sample will distort the curve, making it internally inconsistent and no longer relevant. To inform the user, disclosure of the sample age would be required. To summarise, in a market with low and variable liquidity:

- A curve should have few parameters, be stable and asymptotic at the long end, have a limited number of inflection points;

- The age of the sample should responds flexibly to the liquidity of the market;

- The users need to be informed about the age of the sample and the goodness-of-fit.

Finally, responding to the methodology used by KASE (see Section 4), we add the following requirements:

- Simplicity, transparency and reproducibility of the methodology;

- Ability to reflect the curve in an abstract canonical form, independent of specific securities. 


\subsection{Canonic notions of term structure of interest rates}

There are four canonical representations of the term structure of interest rates: discount curve $d(t)$, zero-coupon curve $z(t)$, forward rate curve $f(t)$, and the par yield curve $w(t)$. Each uniquely defines the other and contains the same information. The discount curve defines today's value of a payment on the future date $t$. The zero-coupon, or spot, yield curve determines the yield on a single payment (or, zero-coupon bond). The discount rate and zero-coupon yield are functionally related at every maturity, regardless of the shape of the curve at that or any other maturity. The forward rate is defined as an instant yield and is calculated from zero-coupon by differentiation. The zero-coupon yield can be expressed as the time averaged forward rate. Equivalently, the forward rate accumulated from the present date to maturity is the zero-coupon rate. More specifically:

$$
\begin{gathered}
z(t)=\frac{1}{t} \int_{0}^{t} f(s) d s=-\frac{1}{t} \ln (d(t)), \\
d(t)=\exp \left(-\int_{0}^{t} f(s) d s\right)=\exp (-t \cdot z(t)), \\
f(t)=\frac{\partial}{\partial t} \ln (-d(t))=z(t)+t \cdot z^{\prime}(t) .
\end{gathered}
$$

Of these, the most common is the zero-coupon curve. Somewhat apart from the three above is the par yield curve $w(t)$, which is defined as the yield to maturity of a hypothetical security traded at par, or put differently, the yield to maturity of a hypothetical security that equals to the coupon rate $w(t)$. That is, it solves the following equation with respect to $w$ for a given discount curve $d$ :

$$
1=w(t) \int_{0}^{t} d(s) d s+d(t) .
$$

The unity on the left-hand side indicates that the security is traded at par. The right-hand side consists of the continuous flow of coupon at rate $w(t)$, discounted by $d(s)$ and accumulated over time, and the principal payment discounted by $d(t)$.

\subsection{Approximating functions: splines vs parametric curves}

The practice of yield curve modelling distinguishes two types of approximating functions for canonic representations: piece wise continuous approximations, or splines, and parametric functions. The few approximating curves that do not fall into these two categories are either hybrids (Faria and Almeida, 2017) or noncanonic representations. 
Splines represent the yield curve as a sequence of approximating polynomials, each defined over an interval bounded by two adjacent knot points, with various continuity requirements at knot points. The most common are cubic splines with continuous curvature. Cubic splines are defined by the base or a list of parameters, including the level, slope and curvature at the starting point and constant third derivatives for each interval between the knot points. McCulloch (1971) was first to apply splines (cubic) to modelling yield curves. Parameters were estimated by minimising the mean squared error. The methodology offered very good insample fit, the more knot points the better, but had poor out-of-sample fit and oscillating forward rates, which tended to deteriorate with more knot points. To tackle this, Fisher et al. (1995) regularised the least squares (the regression splines) by adding a roughness penalty in the form of an integral of squared second derivative over the maturity domain (smoothing splines). The trade-off between the goodness of fit and the robustness under the proposed regularisation scheme was controlled by one parameter, same for all maturities. This tended to underfit the short end, which needed to be more flexible, and overfit the long end. To address that, Waggoner (1997) proposed varying the penalty parameter depending on maturity, the so called variable roughness penalty.

Parametric models are at the other end of the spectrum. The most iconic is Nelson and Siegel (1987; NSS) and its extension by Svensson (1995; NS). Often preferred by central banks (Bank for International Settlements, 2005), NelsonSiegel (NS) parametrisation has broadly recognised practical and empirical advantages: it is easy to estimate, it fits most data well, it has few parameters and intuitive interpretation (Nelson and Seigel, 1987), it closely matches the principle components of the term structure of the interest rate (Diebold and Rudebusch, 2013). This also makes it useful for forecasting the yields (Diebold and Li, 2006). It is consistent with a certain class of theoretical asset pricing models; for example, Krippner (2010) derives NS curve from a Taylor approximation of a Gaussian affine term structure model due to Dai and Singleton (2002).

In liquid markets, the rigidity of NS makes it difficult to compete with splines on fit, in-sample or out-of-sample. An inflexible NS curve is better suited to the priorities of an illiquid market. NS may not show everything that goes on in the market but it is also less likely to overfit and show what is not there. However, when observations are sparse, the rigidity of NS produces an undesirable sideeffect: a spike at the short end of the curve could pivot it around the middle part and sink the long end, tethered loosely by observations only.

More flexible versions of parametric curves are often ad hoc extensions of NS and help dealing with this spurious effect. For example, since 2005 (Gambarov et al., 2004), the Moscow Exchange used NS with three bell-shaped components, with various modes, and in 2017 began to use a curve with 13 parameters, four NSS and nine additional bell-shaped components (Moscow Exchange, 2017). The bells allowed the curve to accommodate the local and 
transient anomalies as perturbations to the otherwise rigid and stable NS without spurious side-effects.

Nelson-Siegel approximates forward curve $f$ by using a constant and a Laguerre function:

$$
f(t)=\beta_{0}+\beta_{1} \exp \left(-\frac{t}{\tau}\right)+\beta_{2} \frac{t}{\tau} \exp \left(-\frac{t}{\tau}\right),
$$

where $t$ is time to maturity, $\beta_{0}, \beta_{1}, \beta_{2}, \tau$ - parameters. Coefficients $\beta_{0}, \beta_{1}, \beta_{2}$ reflect the contribution of the long-term rate $\beta_{0}$, the short-term exponentially decaying component and the medium-term hump peaking at $\tau$.

Transformations (1)-(3), once applied to (5), produce NS parametrisation for spot-curve and discount function:

$$
\begin{gathered}
z(b, t)=\beta_{0}+\left(\beta_{1}+\beta_{2}\right) \frac{\tau}{t}\left[1-\exp \left(-\frac{t}{\tau}\right)\right]-\beta_{2} \exp \left(-\frac{t}{\tau}\right) \\
d(b, t)=\exp \left(-t\left[\beta_{0}+\left(\beta_{1}+\beta_{2}\right) \frac{\tau}{t}\left\{1-\exp \left(-\frac{t}{\tau}\right)\right\}-\beta_{2} \exp \left(-\frac{t}{\tau}\right)\right]\right) .
\end{gathered}
$$

The second and third components of (6) converge asymptotically to zero (Figure 2). As Diebold and Li (2006) showed, NS parameters $\beta_{0}, \beta_{1}, \beta_{2}$ can be interpreted as latent factors that jointly describe the level and slope of the curve, as well as the magnitude and the term of the hump. Thus, the rates at the short end of the curve $f(0)=z(0)=\beta_{0}+\beta_{1}$ are determined by parameters $\beta_{0}$ and $\beta_{1}$. Parameter $\beta_{2}$ determines the size and the direction of the hump in the spot-curve. Parameter $\tau$ could be interpreted as a horizon of the hump.

In practice $\tau$ is often fixed at some level that results in the best fit for the entire period. For example, Diebold and Li (2006) set $\tau$ at 1.4 years. If $\tau$ is optimized for each date, its value remains fairly stable, and so fixing it does not sacrifice much in terms of goodness-of-fit.

Figure 2. Decomposition of zero-coupon curve into three NS components

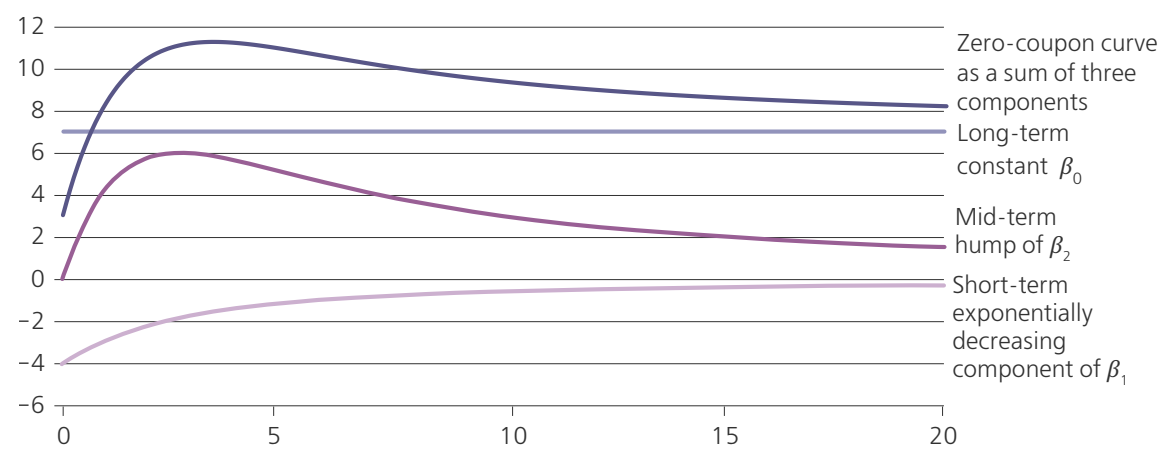

Source: authors' calculations and graphical representation 


\subsection{Sample preparation}

Tasked with building a curve in a market with 'low and heterogeneous liquidity that distorts prices', Gambarov et al. (2004) set out to make corrections to the observations before using them to estimate the parameters of the curve. They exclude securities that are not liquid enough when compared to others by an index of frequency and volume of trade. They differentiate the remaining issues by accounting for and estimating a liquidity premium and by assigning greater weight to more liquid issues. The parameters of the curve are adjusted in response to any new transaction (or best quote) that departs from the current curve using the Kalman filter.

\section{KASE's old methodology}

In September 2019, KASE adopted the methodology proposed in this paper, with some minor changes (KASE, 2019). However, before that the KASE used a methodology adopted in 2011 (KASE, 2011) that was one of the motivations for this research.

According to the KASE 2011 methodology, a curve resulted from a series of disconnected regressions of yield to maturity on maturity. Its objective, as well as the objective of the earlier methodology (KASE, 2003), did not meet the requirements discussed above. KASE wanted the curve to help observers to identify 'market prices'. KASE accepted government debt as collateral in KASE intermediated repo. The regulator used these 'market prices' to evaluate government securities in the portfolio of commercial banks and regulated investors. The curve was published as a list of securities with clean 'market price' and yield to maturity.

Starting from 2011, the KASE curve was constructed as a piecewise polynomial approximation. Previously, under KASE 2003 it was approximated as a 'logarithmic trend' at the short end and a constant coefficient at the long end (KASE, 2003). The boundaries of maturity intervals ('subgroups'), over which polynomials were defined, and the length of the sample ('base period') for each interval were set by the Expert Committee of the Stock Exchange at least once a quarter. Maturity intervals and the age of the sample defined the sample of observations for each polynomial.

The number of intervals could vary from one to three. Polynomials could not be higher than third order. There were no rules to uniquely determine the number of intervals, their boundaries and the order of the polynomials. These decisions were made by the Expert Committee.

One requirement introduced in recent years was the presence of at least 25 days when any security in the corresponding maturity interval was traded in the sample. This condition would be reproducible, if it was not qualified by other conditions that make the sampling process impossible to reproduce. 
Parameters of each polynomial were determined by least squares, for each maturity interval independently of the parameters and data in the adjacent polynomials and without boundary conditions of continuity and smoothness. As a result, the adjacent polynomials differ at the boundaries. To ensure continuity of the approximating function, the adjacent intervals overlap by at least 50 days (as opposed to one point in splines). The value of the approximating function in the overlap zone was defined as a linear combination of the two polynomials, with the weight changing linearly from zero to one within the overlap zone. This ad hoc solution ensured continuity, but not smoothness. In each overlap zone, the slope of the approximating function jumped twice - at the beginning and at the end.

Figure 3 shows the boundaries of maturity intervals used by KASE. Initially, the Expert Committee changed the intervals every month. Sometimes they did not make any changes for several months.

Figure 3. Maturity intervals and overlap zones set by the KASE Expert Committee

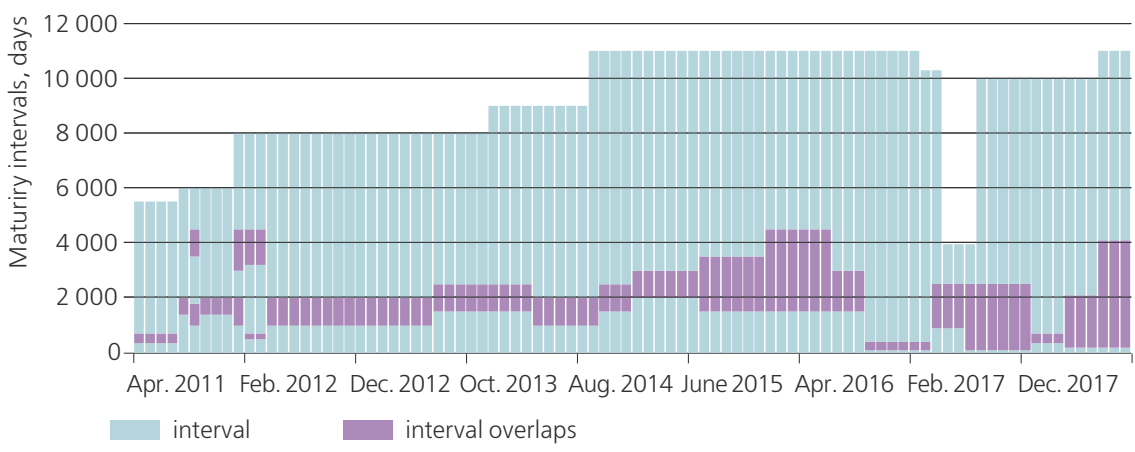

Note: maturity is specified in days. During almost the entire period presented, the curve was approximated at two intervals, with the exception of a few months in 2011-2012 when the KASE Expert Committee identified three intervals. Their overlap zones include observations, which are used to evaluate the two adjacent polynomials. The value of the approximating function in the overlap zone is defined as a weighted average of the values of the two polynomials with the weight determined by the proximity to the boundaries of the overlap zone.

Source: KASE 2011, visual interpretation of the authors

Figure 4 shows the length of sample - the base period - for each maturity interval.

The methodology required excluding observations with a significant deviation from the polynomial, so that $R^{2}$ for the remaining observations was not less than $60 \%$. This led to the discrimination of new information, namely transactions, yields of which significantly differed from the curve. It was clearly observed in 2015-2016 when the monetary policy regime was changed. Transactions that carry information about the changes in the curve were excluded from the sample until enough transactions at a new level had been accumulated.

The disadvantages of such a 'naïve' curve hamper the construction of a conceptually consistent term structure. Lack of smoothness makes forward rates undefined. The arbitrariness and unregulated nature of the procedure for choosing 
the number of intervals, their boundaries and the depth of the history makes the methodology irreproducible. At the publication stage, the curve did not contain information on the age of the sample or the level of market liquidity. Using such a curve as an indicator of 'market prices', deviation from which triggered regulatory scrutiny created additional barriers for liquidity and price discovery.

Figure 5 provides examples of the yield-to-maturity curves published by KASE, which illustrate features of the curve approximation method (no boundary smoothness conditions), the curve presentation and the publication method (the curve is represented as a set of points corresponding to outstanding securities).

Figure 4. Age of the sample at each maturity interval, KASE 2011

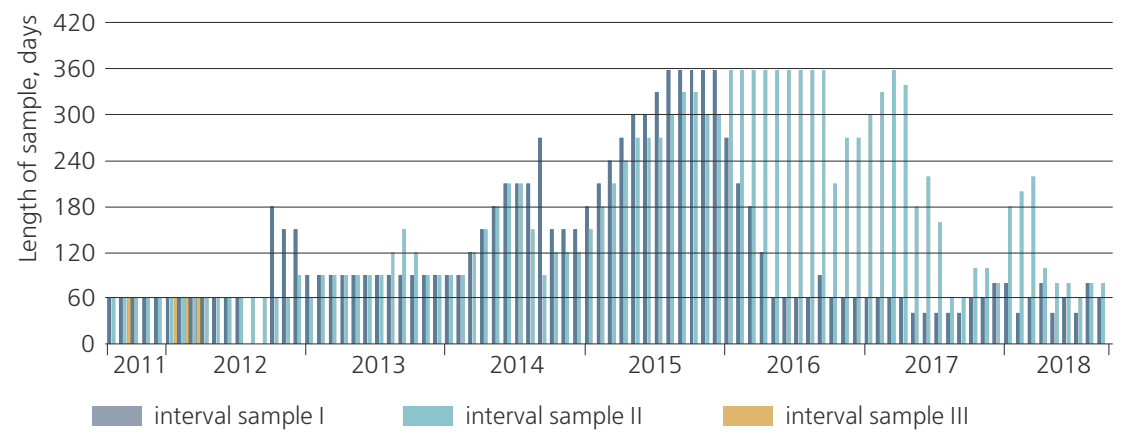

Note: the exceptions to the sampling method were two months in 2012, when the length of sampling for the maturiy interval (I), was determined by the presence of 25 days with transactions in this maturity interval. In 2012Q4, this rule was cancelled and the length of sampling interval (base period) was increased from 60 to 180 days.

Source: KASE 2011, authors' graphic interpretation

Figure 5. Yield to maturity curves, KASE 2011 methodology

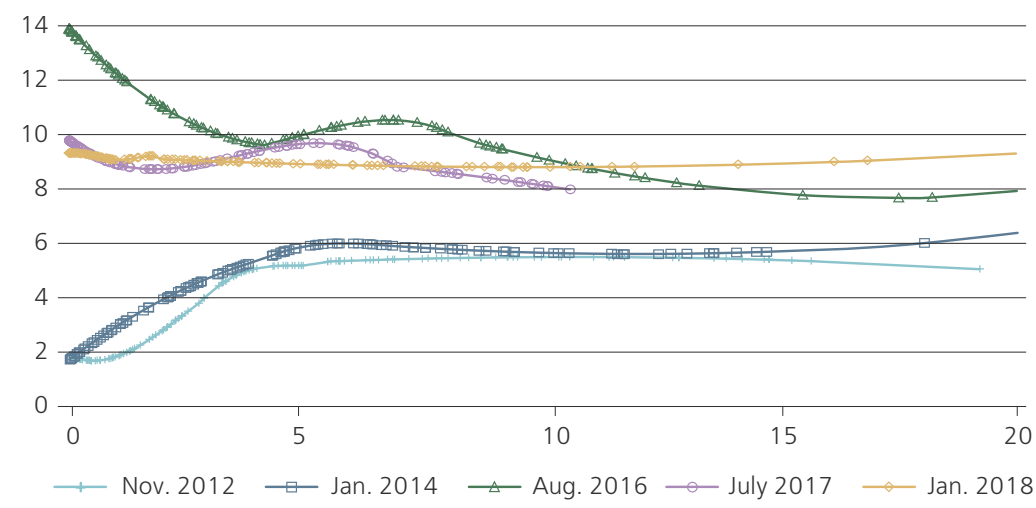

Note: the graph shows files of the 'market value' of government securities for certain dates where the $Y$-axis is yield to maturity and $X$-axis is time left to maturity, based on the 'market price' of the security. Each mark corresponds to a particular security from the list of securities circulating as of the corresponding date, regardless of transactions in the sample. The depth (age) of the sample for the corresponding date can be determined from the Figure 4. Since KASE did not publish the parameters of the approximating function, the values between the points are linear interpolation.

Source: KASE, authors' graphic interpretation 
Figure 6 illustrates the features of the KASE methodology when we try to build a forward curve on its basis. The constructed forward rates are unstable and sometimes negative. Discontinuity at terms under 6 years is due to the fact that the curve is presented not as a continuous object, but a list of securities. As a result, the accuracy of estimated forward rates depends on the distribution of maturities of securities in circulation. Negative rates at 11-12 years result from discontinuity of the curve's slope in the overlap zones.

Figure 6. Forward curve, derived from the KASE 2011 yield curve as of 28 March 2016

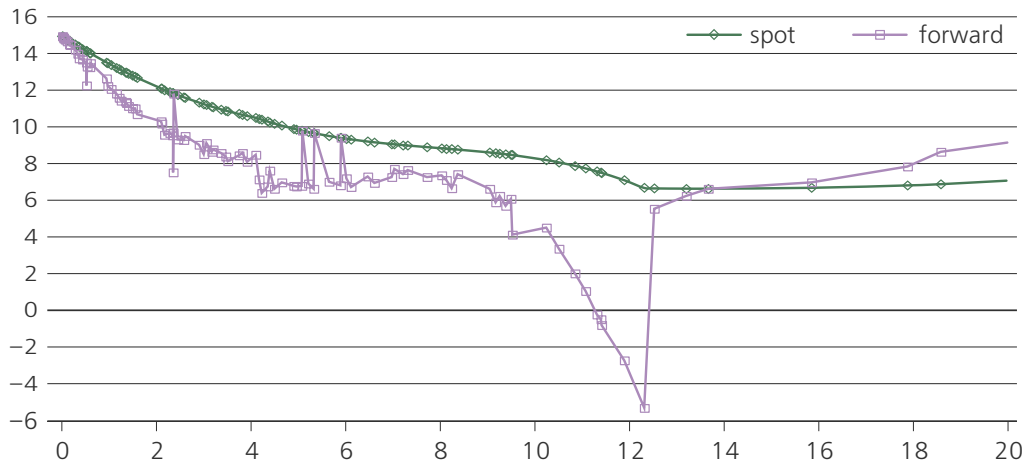

Source: data on 'Market valuation' of yield to maturity available from KASE website, authors' calculations and graphic representation

\section{Proposed Methodology}

\subsection{Parametrisation}

We chose a standard Nelson-Siegel parametric curve because of its parsimony and certain rigidity that ensures good out-of-sample fit, which we associate with stability and robustness. NS is an almost ideal parametrisation for illiquid and inefficient markets. Its rigidity helps it to filter noise when the signal-to-noise ratio is low. When noise is overwhelming and frequency of observations is low, deviations due to asynchronicity of observations and due to inefficiency of the market become difficult to distinguish.

\subsection{Stratification by maturity}

Similarly to the KASE 2011 method, we separate the sample into subsamples, depending on maturity of observations. Unlike KASE, the number and boundaries of maturity intervals are fixed for simplicity and better reproducibility. The number of intervals should exceed the number of parameters and the boundaries should approximately follow a geometric series. The first condition is a precaution 
against under-determination. The second condition is meant to achieve a similar frequency of transactions in each interval, and by extension, a similar age of the subsample. We set the number of intervals to four because having more than four intervals made the sample older with little gain in stability. The boundaries of subsamples are set at six months, one, and five years.

\subsection{Age of the sample}

In the Kazakhstan market, the frequency of transactions strongly depends on maturity and varies over time. Figure 7 illustrates these two features of the Kazakhstan government securities market. Low level of liquidity in 2010 was particularly low in the short term. Liquidity decreased sharply in 2013 and continued to decline, and market activity almost completely ceased in 2015 . KASE responded to this by making the sample older.

Figure 7. Frequency of transactions with government securities on semiannual basis

\begin{tabular}{|c|c|c|c|c|c|c|c|c|c|c|c|c|c|c|c|}
\hline July 10 & 10 & 23 & 34 & 44 & 101 & 113 & 199 & 76 & 132 & 47 & 37 & 58 & 116 & 69 & 104 \\
\hline Jan. 11 & 3 & 23 & 18 & 49 & 56 & 53 & 49 & 80 & 80 & 120 & 111 & 71 & 81 & 109 & 160 \\
\hline July 11 & 2 & 32 & 93 & 51 & 94 & 21 & 8 & 20 & 25 & 46 & 45 & 63 & 66 & 17 & 114 \\
\hline Jan. 12 & 0 & 27 & 36 & 39 & 51 & 19 & 59 & 8 & 68 & 7 & 19 & 9 & 20 & 5 & 165 \\
\hline July 12 & 1 & 6 & 20 & 37 & 50 & 12 & 20 & 26 & 21 & 21 & 10 & 6 & 23 & 54 & 244 \\
\hline Jan. 13 & 0 & 1 & 7 & 11 & 38 & 13 & 44 & 56 & 24 & 22 & 19 & 3 & 9 & 25 & 73 \\
\hline July 13 & 0 & 3 & 3 & 12 & 36 & 13 & 13 & 16 & 34 & 42 & 34 & 9 & 5 & 8 & 43 \\
\hline Jan. 14 & 0 & 0 & 7 & 20 & 24 & 23 & 29 & 21 & 29 & 23 & 16 & 35 & 15 & 13 & 34 \\
\hline July 14 & 0 & 1 & 2 & 3 & 9 & 8 & 6 & 8 & 6 & 17 & 5 & 16 & 9 & 20 & 60 \\
\hline Jan. 15 & 0 & 0 & 4 & 12 & 8 & 21 & 17 & 30 & 41 & 16 & 6 & 6 & 7 & 5 & 73 \\
\hline July 15 & 0 & 1 & 0 & 1 & 0 & 0 & 1 & 0 & 1 & 0 & 1 & 1 & 0 & 1 & 11 \\
\hline Jan. 16 & 2 & 8 & 0 & 1 & 0 & 0 & 3 & 0 & 0 & 2 & 2 & 2 & 0 & 0 & 11 \\
\hline July 16 & 91 & 104 & 15 & 5 & 5 & 0 & 0 & 0 & 2 & 3 & 1 & 2 & 0 & 0 & 10 \\
\hline Jan. 17 & 1440 & 575 & 94 & 131 & 209 & 9 & 6 & 6 & 5 & 0 & 1 & 0 & 0 & 0 & 0 \\
\hline July 17 & 1044 & 491 & 21 & 125 & 239 & 2 & 5 & 9 & 4 & 0 & 3 & 0 & 0 & 1 & 2 \\
\hline Jan. 18 & 462 & 340 & 12 & 86 & 153 & 20 & 7 & 16 & 9 & 10 & 4 & 0 & 5 & 4 & 19 \\
\hline July 18 & 481 & 500 & 41 & 94 & 276 & 31 & 11 & 27 & 1 & 18 & 21 & 5 & 15 & 6 & 57 \\
\hline & $\begin{array}{l}\frac{n}{\pi} \\
\frac{\pi}{0} \\
\hat{v}\end{array}$ & $\begin{array}{l}\stackrel{n}{\sigma} \\
\frac{\pi}{0} \\
\circ \\
m \\
v\end{array}$ & 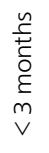 & \begin{tabular}{l}
$\tilde{n}$ \\
$\stackrel{+}{+}$ \\
\multicolumn{1}{c}{} \\
$\varepsilon$ \\
$\sigma$ \\
$v$
\end{tabular} & 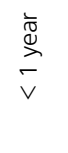 & 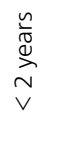 & 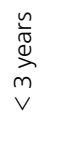 & $\begin{array}{l}\stackrel{\sim}{\nabla} \\
\stackrel{\otimes}{\curvearrowright} \\
\vee\end{array}$ & 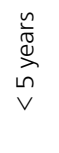 & 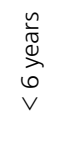 & 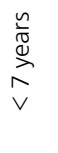 & $\begin{array}{l}\stackrel{n}{\frac{\pi}{\sigma}} \\
\stackrel{\infty}{\alpha} \\
\infty \\
v\end{array}$ & 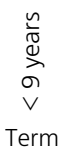 & 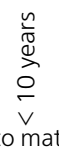 & $\stackrel{t}{\circ}$ \\
\hline
\end{tabular}

Source: KASE, authors' calculations

We applied a similar principle: for each maturity range, the subsample is composed of the ten most recent transactions, but not older than 360 days (Figure 3).

A less explicit way to incorporate older observations is to update the curve dynamically, using the Kalman filter, as new information becomes available. Cortazar et al. (2007) used the Kalman filter to estimate parameters of a dynamic term structure model by using incomplete panel data. Gambarov et al. (2004) 
used a similar approach to estimate parameters of the NS model. This approach, however, lacks an explicit indicator of the age of the sample or of the curve.

\subsection{Weighting}

The weight of a transaction depends on its age relative to the oldest transaction in the sample and on the log of volume. All four subsamples have equal weight. Inside the maturity interval that defines the subsample, the weight decreases exponentially with age so that the oldest transaction in the sample weighs a tenth of a transaction on the date of the curve.

Figure 8. Age of the subsample and the number of transactions in each maturity interval
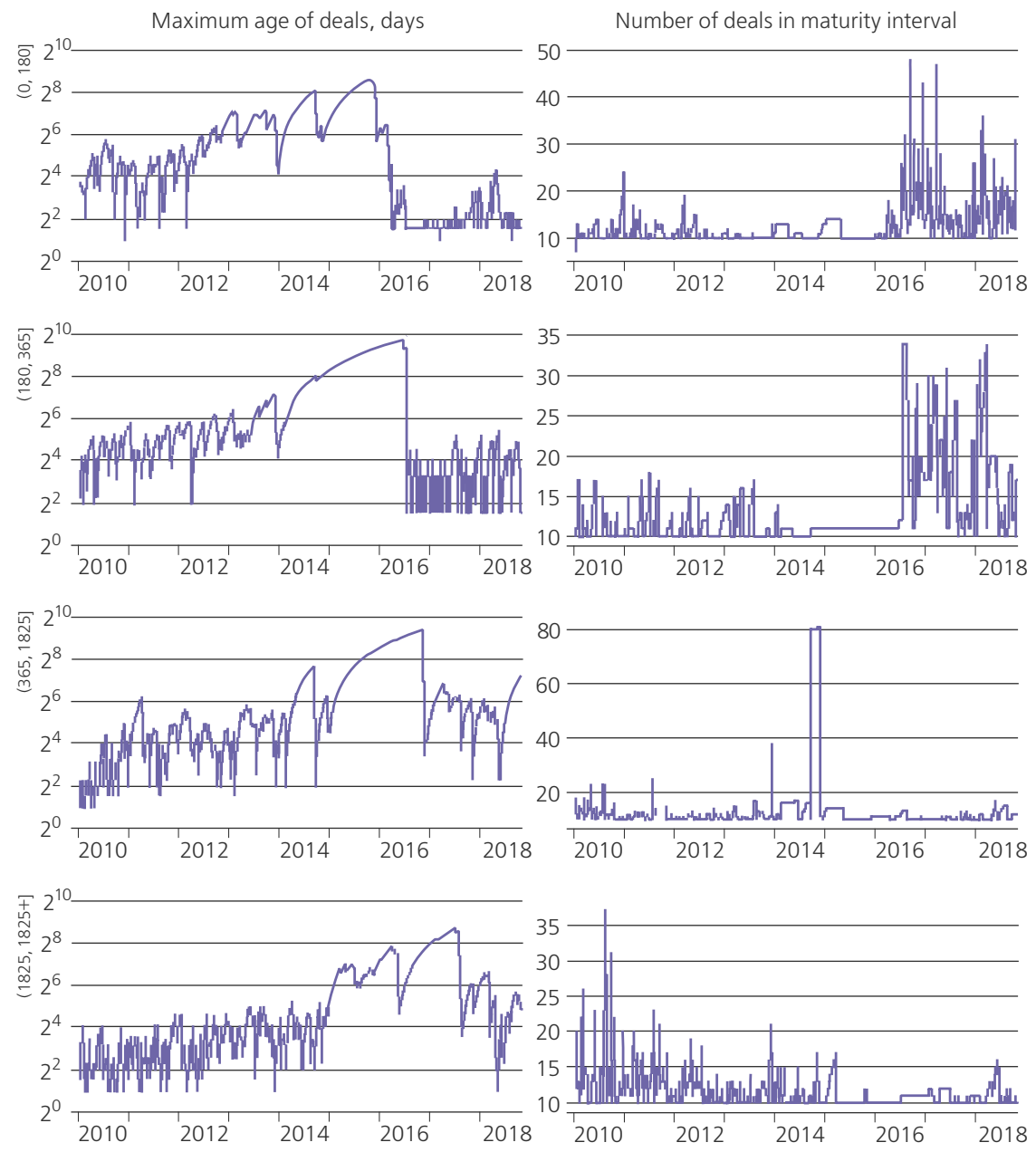

Note: plotted based on data of 4 baskets, on weekly basis.

Source: KASE, NBK calculations 
The sample is formed as follows:

1. All observations are separated into maturity intervals, depending on the maturity. The intervals are taken as follows: [8-180], [181-365], [366-1825], [1826-1826+], in days;

2. 10 recent transactions are selected in each maturity interval;

3. The total weight of each subsample is assumed being equal to one-fourth. Within the subsample, weights are determined in proportion to the logarithm of the transaction volume and an exponential decay, the rate of which is determined by the age of the sample.

For the first subsample, we exclude the transactions with maturity of less than 7 days motivated by pricing inefficiencies and nearly absent secondary market. For all other subsamples, we did not exclude any security or transaction based on its maturity. For example, excluding securities with the remaining maturities less than one year, similar to Gürkaynak, Sack and Wright (2007; GSW), would exclude the most liquid segment of the market.

\subsection{Comparison with a standard sampling method}

GSW (2007) use a sampling procedure that is typical in a liquid market. Their sample consists of all off-the-run issues outstanding and their end-ofday price quote. This choice would reliably and automatically produce a sample that is representative of all maturities simply because the US Treasury schedules securities in circulation to have evenly spaced maturity dates and every issue is quoted daily.

Kazakhstan's market is far less liquid. Our unit of observation is a transaction with any fixed income security. Had we instead used a security as the unit of observation, GSW style, our sample would be full of missing values or very old observations because in an illiquid market many securities in circulation are not traded after placement and those few that are, are traded infrequently and quoted sporadically. During 2013-2015, there were periods of several days long with no transactions in any issue of any maturity. In some periods, the primary and onthe-run market constituted the only activity. Excluding them would make the sample even smaller. Tables $1 \mathrm{a}$ and $1 \mathrm{~b}$ provide some statistics about the frequency of trade and quotation for the most traded security.

We have had to stratify the sample by dividing into four maturity baskets so that each contained equal number of observations. Had we not stratified the sample, the least liquid part of the curve would be severely underrepresented and, most likely, unstable. A rigid curve such as NS tends to translate a spike at the short end into a drop at the long end because the observations in the middle part act as a pivot. Figure 7 provides some indication about which maturity would dominate the sample in a given period. Figure 9 illustrates how a large variance of the observed yields at the short and long ends could produce negative correlation between the two ends. 
GSW did not report the data on bid-ask spread, frequency of transactions, treatment of the missing data. The fact that these questions are not discussed is indicative of a market where a missing data event is too rare to merit special handling, and where bid-ask spreads are narrow enough to make no difference between the mid-spread and the transaction price.

A related issue is keeping track of the dates and the age of transactions. Had we tried using end-of-day quotes for all off-the-run issues, we would not be able to find enough data points to fit the curve to.

Figure 9. A sample on 7 December 2015 by yield and term to maturity

Transactions by yield and term to maturity

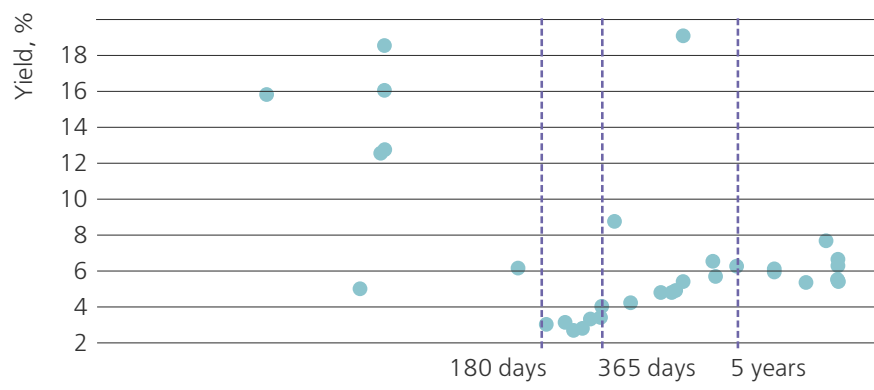

Term to maturity (log, base 2)

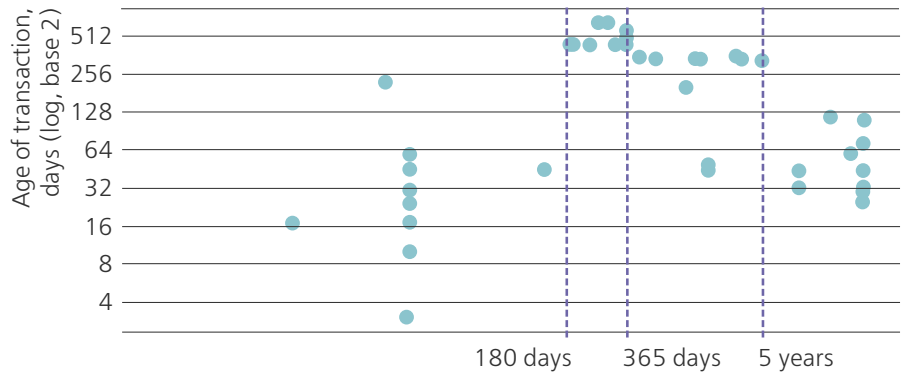

Source: KASE data, authors' representation

\subsection{Parameter estimation}

The choice of $b=\left(\beta_{0}, \beta_{1}, \beta_{2}, \tau\right)$ should minimise the weighted sum of squared residuals between the fitted and the actual yield to maturity. That is, $\hat{b}$ solves

$$
\min _{b} \sum_{i}\left(y(i, b)-y_{i}\right)^{2} * w_{i},
$$

where $w$ - vector of weights by observation; $y$ - vector of actual yield to maturity for the transactions in sample, corresponding to the actual dirty price $p ; y(b)$ - vector 
of yield to maturity according to the curve defined by the parameters $b$. The dimension of the vectors is equal to the sample size.

The element of this vector $y(b)$, corresponding to transaction $i$, solves the following equation with respect to $y$ :

$$
p(i, b)=\sum_{j} e^{-y t_{i j}} c_{i j}
$$

and equals to the yield of maturity that corresponds to the fitted price $p(i, b)$, defined as the sum of present value of cash flows indexed by $j$ of security $i$, each priced by fitted price $d\left(b, t_{i j}\right)$, defined in (7), at maturity $t_{i j}$ :

$$
p(i, b)=\sum_{j} d\left(b, t_{i j}\right) c_{i j}
$$

Parameters $\beta_{0}, \beta_{1}, \beta_{2}$ are found by the non-linear optimisation method. Parameter $\tau$ is determined by a grid on the interval of 0 to 5 years.

The source code and test data in the IRIS information system format are published under the GPLv3 licence on the Github and could be found at the following link: https://github.com/DFSResearch/FinancialStability_Lab

\section{Results}

The methodology of constructing a risk-free yield curve has been applied to the government securities transaction data made available by KASE. Figure 10 compares the curves constructed by KASE 2011 and the curves based on our methodology. KASE 2011 curve has a number of undesirable features: slope discontinuities (every example), negative forwards (August 2016 and January 2018), constant concavity at the long end (January 2014, August 2016, and January 2018).

Figures 11 and 12 illustrate the analytical benefits of NS parametrisation, where the dynamics of the curve could be analysed as the dynamics of the parameters.

A strong negative correlation between $\beta_{0}$ and $\beta_{1}$, significant oscillations of these parameters, especially before 2015 , reflects the high volatility of the short-term rate, $\beta_{0}+\beta_{1}$, during the regime of the pegged exchange rate and the absence of interest rate policy, with occasional interventions of the monetary authority at the short end of the curve. This changed after the National Bank began to manage the money market rate, which resulted in a sharp reduction of volatility of short-term rates.

Figure 11 shows that the volatility and the spikes of the money market are not reflected at the short-term end of the yield curve because of the absence of a link between yields on money market and government securities market for that moment. 
Figure 10. Comparison of the zero-coupon NS curve and the KASE 2011 methodology

Nov 2012

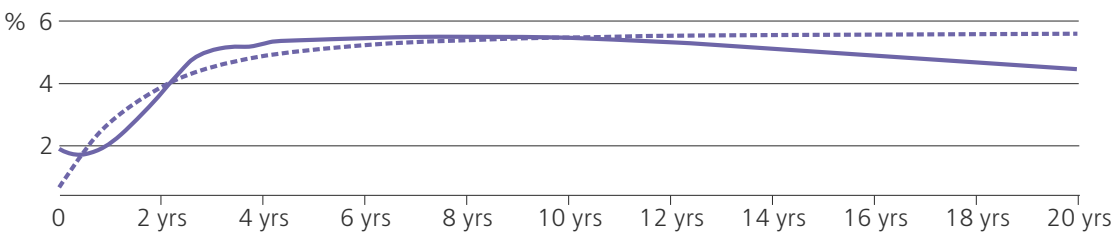

$\operatorname{Jan} 2014$
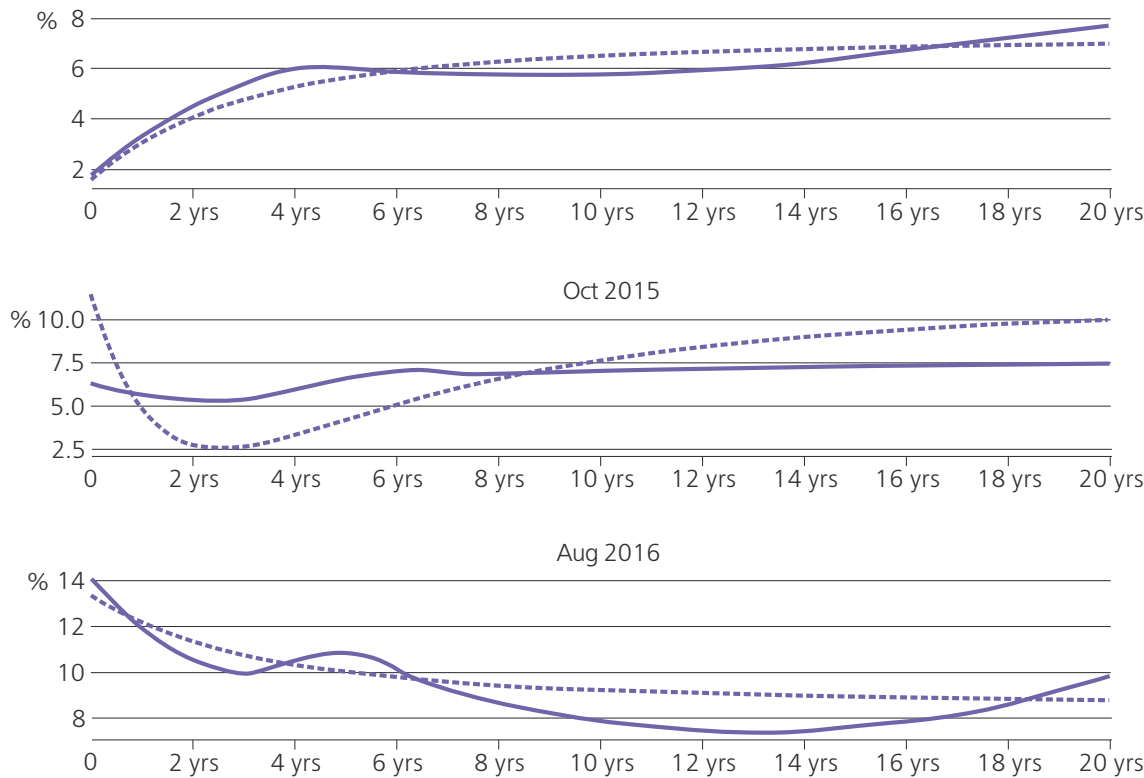

Jan 2018

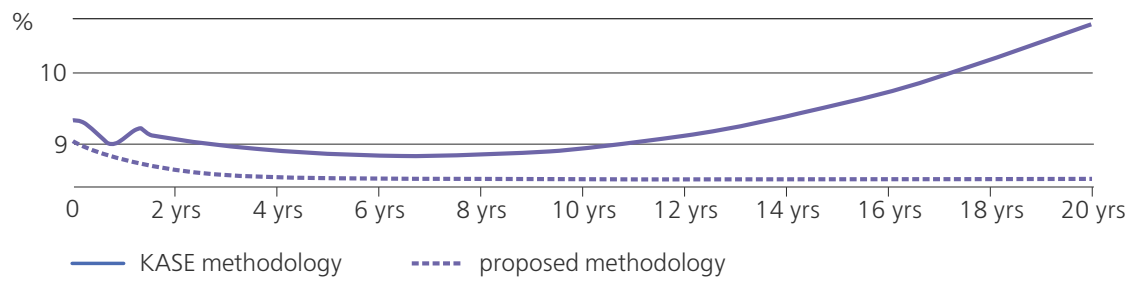

Source: KASE, NBK calculations

\subsection{Comparison with Svensson}

Figure 13 and 14 compare NS with Svensson using the same sample and same criteria, goodness-of-fit and stability over time. As expected, Svensson has better fit, but not by much. However, NS is marginally more stable. 
Figure 11. Money market rates and the short-term rate of the fitted NS curve

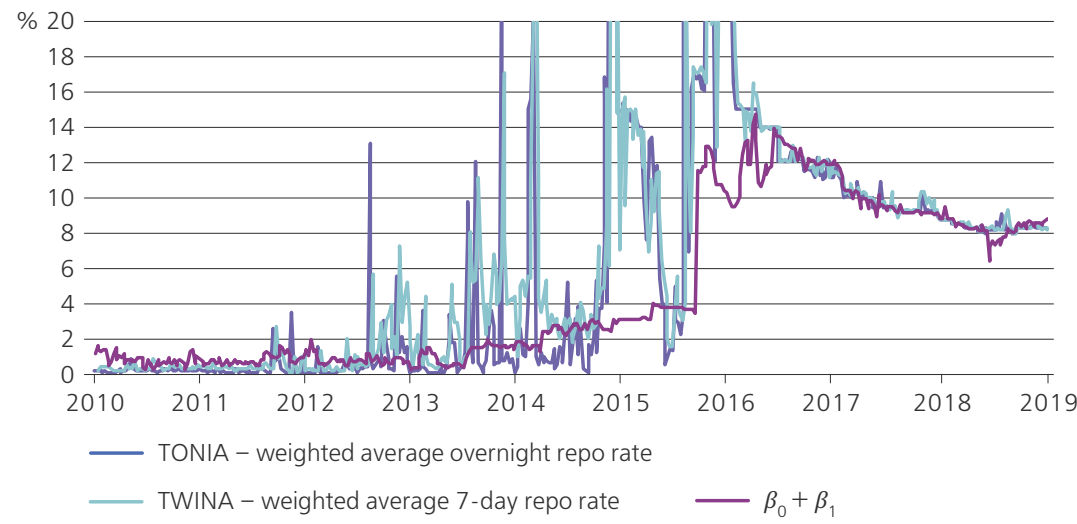

Source: KASE data, autors' calculations

Figure 12. Dynamics of Nelson-Siegel parameters
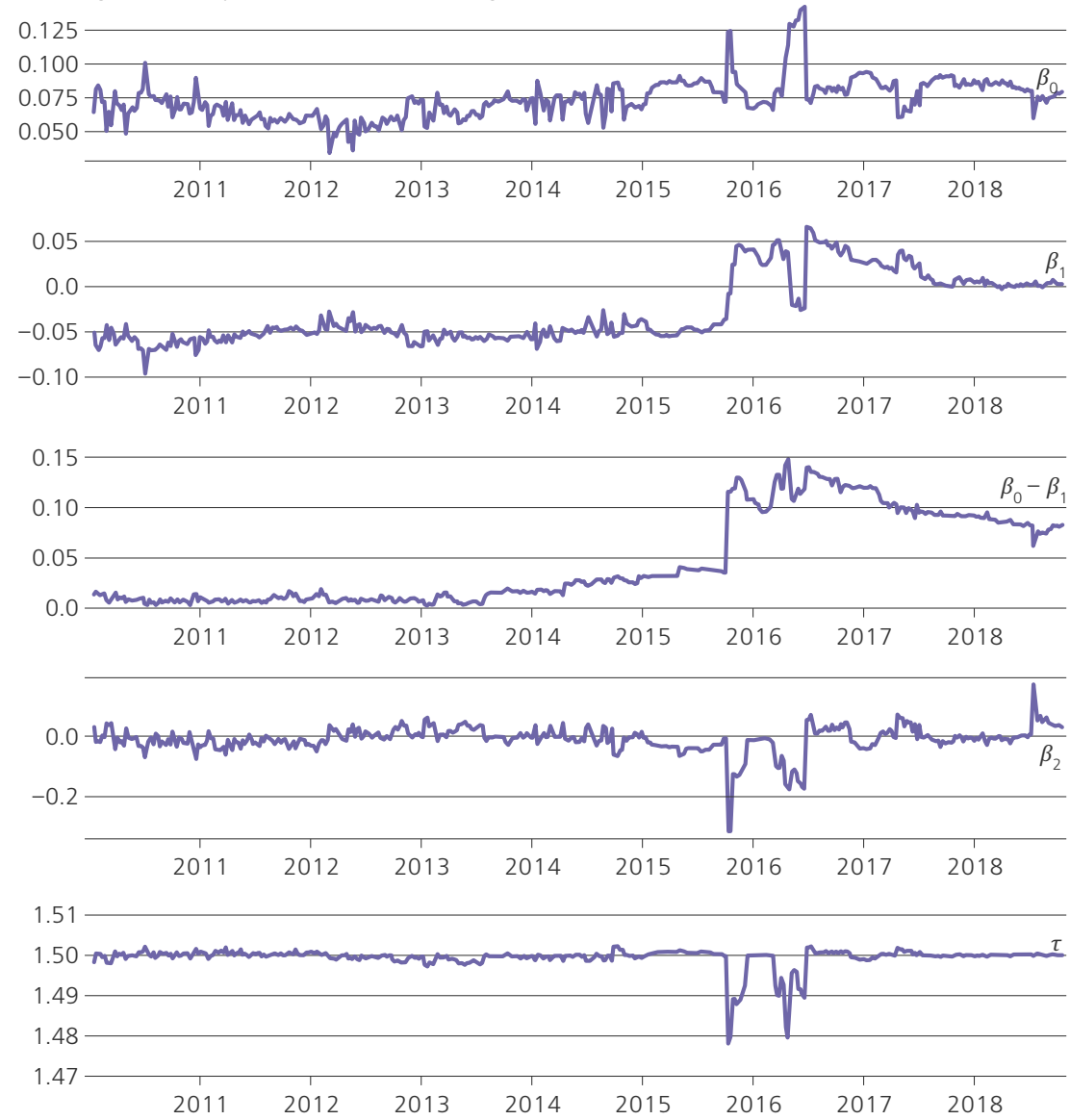

Source: KASE, NBK calculations 
Figure 13. Goodness-of-fit for NS and Svensson, p.p.

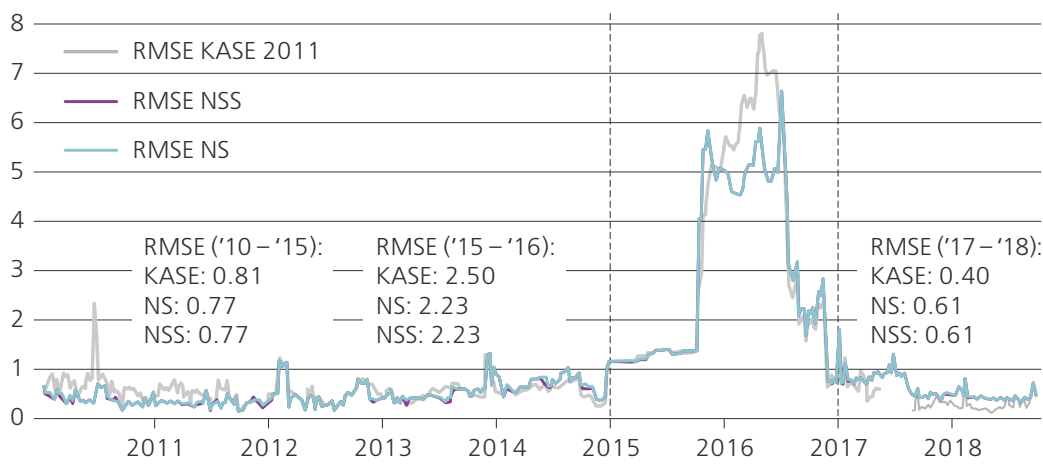

Source: authors' calculations

Note, however, the magnitude of the mean squared error (RMSE) at some point in time is greater than 5 p.p. In the last two years (2017-2018), the RMSE declined to the levels of 2015 but remains large at about 50-100 b.p. This is two orders of magnitude greater than the RMSE of NS in developed markets. We ascribe it to inefficiency of the market that makes the rate dependent on factors other than maturity rather than to inability of the curve to describe the relationship between the yield and maturity.

As a metric of stability, we use the root mean squared of the change in the spot rate on date $t$ relative to date $t-1$ five-period tracking average spot rate for twelve maturities from 7 days to 20 years. That is,

$$
R M S E_{t}=\sqrt{\frac{1}{N} \sum_{j=1, N}\left(z_{j t}-M A\left(z_{j, t-1}, 5\right)\right)^{2}},
$$

where $z_{j t}$ is the spot rate at maturity indexed by $j$, which goes through $N=12$ maturities; $M A(\cdot, 5)$ denotes a five-week moving average operator.

Table 4. RMSE of weekly change, p.p.

\begin{tabular}{c|c|c|c} 
& NS & Svensson & NS-Svensson \\
\hline Jan 2010 - Sept 2015 & 0.21 & 0.24 & -0.03 \\
\hline Oct 2015 - Sept 2016 & 0.69 & 0.69 & -0.00 \\
\hline Oct 2016 - Sept 2018 & 0.15 & 0.16 & -0.01 \\
\hline
\end{tabular}

Figure 14 illustrates this stability metric for NS curve and its difference from the same metric for NSS. Averaged over a sufficiently long period this metric is our gauge of a curve's stability (Table 4). A smaller value of RMSE of weekly change corresponds to a more stable curve. NS changes are less than NSS ones on most weeks as indicated by the predominance of negative difference between the weekly change of NS and of NSS (below-zero area under the curve in Figure 14). During the intermediate turbulent transition, there is no difference in terms of 
stability between the two parametrisations. On the dates when NS is less stable than Svensson, the difference between the two curves is small. However, when NS is more stable, its advantage is very pronounced. The outperformance of NS in terms of stability has waned over the last two years.

Figure 14. Stability of NS and NSS spot rate curves, p.p.

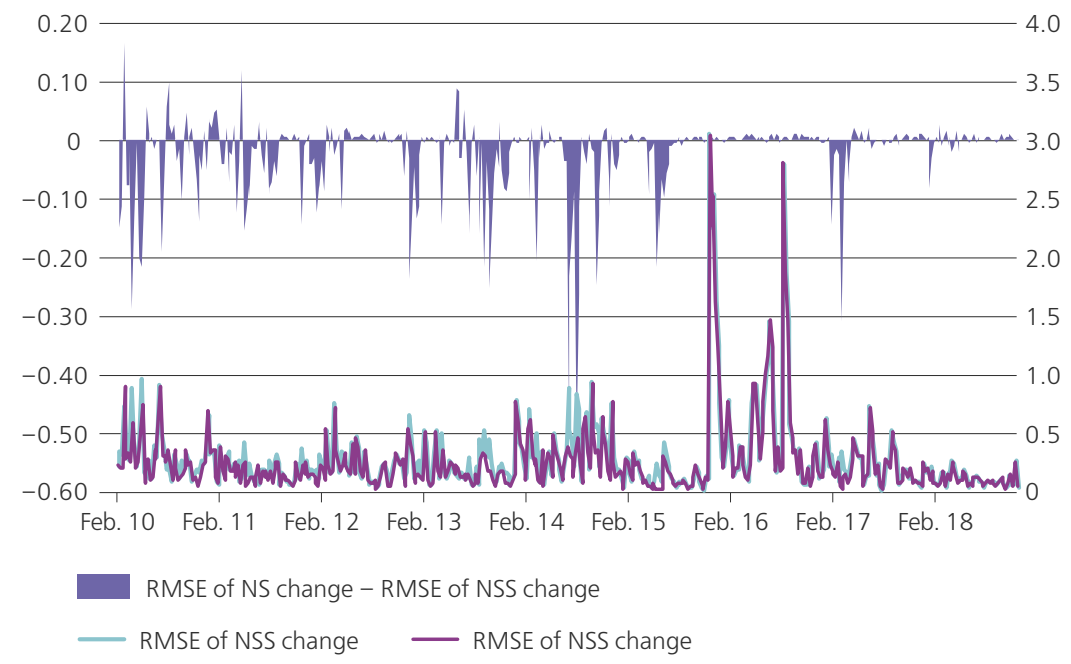

Source: authors' calculations

\subsection{Comparison with KASE 2011}

Unlike the KASE 2011 methodology, the proposed methodology is algorithmic, reproducible and transparent. It outputs canonical representations of the yield curve, which guarantee unique fitted value for price or YTM for any security. The use of NS specification ensured that all curves are continuous and smooth (and infinitely differentiable). Parsimony of representation lowers the sample size requirements and substantially improves stability and robustness.

Our sampling procedure of 'the ten most recent observations in each maturity interval' is fully reproducible and automatically extends or shortens the age of the sample, depending on liquidity.

Both methodologies increase the length of the sample in order to obtain a sufficient number of observations. In both cases, the sample is separated into subsamples to account for differences in liquidities in different maturities. KASE 2011 requires at least 25 days with transactions in each of the two intervals. We require 10 transactions in each of the four maturity intervals. The differences in the sampling technique are not significant enough to make the comparison uninformative. The two methods should have a roughly equal number of observations: KASE 2011 uses at least 50 and we use at least 40. 
Our model is simpler than KASE's, it has fewer parameters and can be easily reproduced. It is more stable than KASE 2011, except during the transition to a new monetary policy regime. More detailed comparison of methodologies is presented in Table 5 below.

Table 5. Comparative analysis of the current and proposed methodologies

\begin{tabular}{|c|c|c|}
\hline & KASE 2011 methodology & Proposed methodology \\
\hline \multicolumn{3}{|c|}{ Shape and concept of the curve } \\
\hline Type of the curve & $\begin{array}{l}\text { YTM (bond specific) vs maturity } \\
\text { ('naïve' YTM) }\end{array}$ & $\begin{array}{l}\text { Canonical representations (spot, YTM } \\
\text { (par), forward, discount vs maturity) }\end{array}$ \\
\hline Approximating function & $\begin{array}{l}\text { Piecewise polynomial of order up } 3 \text {, } \\
\text { distinct for each interval }\end{array}$ & Nelson-Siegel \\
\hline Intervals & $\begin{array}{l}2 \text { or more intervals, overlap 50+ day, set } \\
\text { by Expert Committee }\end{array}$ & Not relevant \\
\hline Continuity & Yes, due to weighting in overlap zones & Yes \\
\hline Smoothness & No. Slope discontinuity at knot points & Yes \\
\hline $\begin{array}{l}\text { Requirement of non- } \\
\text { negativity of forward rates }\end{array}$ & $\begin{array}{l}\text { No. Often negative implied forward rates } \\
\text { at knot points }\end{array}$ & $\begin{array}{l}\text { No, but has not been observed in our } \\
\text { sample }\end{array}$ \\
\hline \multicolumn{3}{|c|}{ Fitting parameters } \\
\hline Number of parameters & $\begin{array}{l}6 \text { and more, } \\
\text { including interval boundaries }\end{array}$ & 4 \\
\hline \multirow[t]{2}{*}{ Goodness-of-fit } & $\begin{array}{l}\text { Square of deviations of fitted and actual } \\
\text { YTMs summed over observations in an } \\
\text { interval }\end{array}$ & $\begin{array}{l}\text { Square of deviations of fitted and actual } \\
\text { YTMs summed over all observations }\end{array}$ \\
\hline & Separate for each subsample & Simultaneous for the entire sample \\
\hline $\begin{array}{l}\text { Simultaneous vs } \\
\text { sequential optimization }\end{array}$ & $\begin{array}{l}\text { Polynomial parameters, intervals, overlap } \\
\text { zones, outliers }\end{array}$ & Nelson-Siegel parameters \\
\hline \multicolumn{3}{|c|}{ Sample } \\
\hline Age of the sample & $\begin{array}{l}\text { Sample should contain at least } 25 \text { days } \\
\text { with trades }\end{array}$ & $\begin{array}{l}\text { The larger of two for each maturity } \\
\text { interval - } 10 \text { most recent or all trades } \\
\text { during the day }\end{array}$ \\
\hline Outliers & Excluding largest deviations until $R^{2}>0.6$ & No \\
\hline \multicolumn{3}{|c|}{ Publication } \\
\hline Frequency & Weekly & Daily \\
\hline Publishing values & $\begin{array}{l}\text { Fitted prices and YTM for the securities } \\
\text { in circulation }\end{array}$ & $\begin{array}{l}\text { Parameters of NS, values of all canonic } \\
\text { curves at focal maturities. RMSE, average } \\
\text { age and age of the ealiest transaction } \\
\text { for each maturity range. }\end{array}$ \\
\hline
\end{tabular}

\section{Conclusion}

In this paper, we present estimates of Kazakhstan's yields curve for a period from 2010 to 2018 on a weekly basis using Nelson-Seigel parametrisation as the approximating function and the transactions with government tengedenominated securities. The results are made public as part of this paper with the intent of providing macroeconomic analysts with interest rate data on Kazakhstan that was not available previously. In this respect, we follow GSW (2007) who provided a similar service for the U.S. Treasury market.

A word of caution is in order. As our discussion of Kazakhstan's market demonstrates, the information that is contained in the yield curve cannot be 
properly interpreted without understanding the institutional and regulatory constraints that the market operates under. For example, yield curves in the less liquid markets add little to the predictive power of macroeconomic models (Mehl, 2006). This is particularly true for a market that is as illiquid and inefficient as Kazakhstan's. We, thus, encourage the users of our dataset to abandon assumptions of market efficiency, pay more attention to RMSE and the age of the sample data and keep in mind the many impediments to efficiency and liquidity that we described at the beginning of the paper.

We should also warn against interpreting the curve as the market demand or the opportunity costs of holding tenge-denominated assets. Our curve is built solely on transactions with government securities and should be interpreted only as an aggregation of that market. A curve that is more representative of the voluntary demand would need to use different data. These could include bid prices, money market, foreign currency forwards, and other related markets. Thus, future work could focus on incorporating the implied yield curve from the non-deliverable forward market or using quote data.

However, there are limits to what can be extracted from a scarce and noisy data. Improvements made to yield curve construction methods will not address the underlying causes of inefficiency. We, thus, encourage the users of our dataset to delve deeper into the analysis of distortions with the aim of dismantling them. If successful, such research would pave the way to a more liquid market and eventually should reduce the need in the yield curve methods included in this paper that specialise in illiquid markets.

\section{References}

Bank for International Settlements (2005). Zero-Coupon Yield Curves: Technical Documentation. BIS Papers, N 25.

Cortazar, G., Schwartz, E. S. and Naranjo, L. F. (2007). Term-Structure Estimation in Markets with Infrequent Trading. International Journal of Finance and Economics, 12(4), pp. 353-369. doi:10.1002/ijfe.317

Dai, Q. and Singleton, K. J. (2002). Expectation Puzzles, Time-Varying Risk Premia, and Affine Models of the Term Structure. Journal of Financial Economics, 63(3), pp. 415-441.

Diebold, F. X. and Li, C. (2006). Forecasting the Term Structure of Government Bond Yields. Journal of Econometrics, 130(2), pp, 337-364.

Diebold, F. X. and Rudebusch, G.D. (2013). Yield Curve Modeling and Forecasting. Princeton, N. J.: Princeton University Press.

Faria, A. and Almeida, C. (2017). A Hybrid Spline-Based Parametric Model for the Yield Curve. Available at SSRN: https://ssrn.com/abstract=2898306 [accessed on 26 November 2019]. 
Fisher, M., Nychka, D. W. and Zervos, D. (1995). Fitting the Term Structure of Interest Rates with Smoothing Splines. Board of Governors of the Federal Reserve System Finance and Economics Discussion Series, N 1.

Gambarov, G., Shevchuk, I., Balabushkin, A. and Nikitin, A. (2004). Zero-Coupon Yield Curve. [In Russian]. Available at: https://www.moex.com/a3644 [accessed on 2 December 2019].

Gürkaynak, R., Sack, B. and Wright, J.H. (2007). The U.S. Treasury Yield Curve: 1961 to the Present. Journal of Monetary Economics, 54(8), pp. 2291-2304. doi: 10.1016/j.jmoneco.2007.06.029

Kazakhstan Stock Exchange (2003). Securities Valuation Methodology.

Kazakhstan Stock Exchange (2011). Securities Valuation Methodology.

Kazakhstan Stock Exchange (2019). Securities Valuation Methodology.

Krippner, L. (2010). A Theoretical Foundation for the Nelson and Siegel Class of Yield Curve Models, and an Empirical Application to US Yield Curve Dynamics. Reserve Bank of New Zealand Discussion Paper Series, N 11.

McCulloch, J. H. (1971). Measuring the Term Structure of Interest Rates. Journal of Business, 44(1), pp. 19-31.

Mehl, A. (2006). The Yield Curve as a Predictor and Emerging Economies. ECB Working Paper Series, N 691.

Moscow Exchange (2017). Methodology of Zero-Coupon Yield Curve for Government Bonds (Federal Debt).

Nelson, C. and Siegel, A. (1987). Parsimonious Modeling of Yield Curves. Journal of Business, 60(4), pp. 473-489.

Nymand-Andersen, P. (2018). Yield Curve Modelling and a Conceptual Framework for Estimating Yield Curve: Evidence from the European Central Bank's Yield Curves. ECB Statistics Paper Series, N 27.

Svensson, L. (1995). Estimating Forward Interest Rates with Extended Nelson-Siegel Method. Sveriges Riksbank Quarterly Review, 3, pp. 13-26.

Waggoner, D. (1997). Spline Methods for Extracting Interest Rate Curves from Coupon Bond Prices. Federal Reserve Bank of Atlanta, Working Paper, N 10. 


\section{APPENDIX}

\section{Algorithm}

1. An observation is a transaction defined as a tuple

$$
\left\langle a_{i}, q_{i}, p_{i},\left(c_{i j}, t_{i j}\right)\right\rangle
$$

where $i$ - index of a transaction,

$j$ - index of a cash flow from a bond transacted,

$a_{i}$ - age of transaction $i$ on the date of the curve,

$q_{i}$ - volume of transaction $i$,

$p_{i}$ - dirty price of transaction $i$,

$c_{i j}$ - cash-flow $j$ from the bond traded in transaction $i$,

$t_{i j}$ - time between the date of the cash flow $j$ from the bond traded in $i$ and the date of $i$.

$c_{i j}$ is equal to half coupon rate (for payment of coupon by semiannually paid coupon bonds) or unity (for payment of principal), $t_{i j}-$ term of coupon and principal payment.

2. Stratify observations into maturity intervals $\left\langle T_{k}^{1}, T_{k}^{2}\right\rangle, k=1,2,3,4$, defined by its boundaries $T_{k}^{1}$ and $T_{k}^{2}$, with $T_{k+1}^{1}=T_{k}^{2}+1$ (intervals are adjacent, but not overlapping), so that the lower limit of interval $k+1$ is one day greater than the upper boundary of interval $k$. When implementing the algorithm, the following interval boundaries were adopted:

$\left\{\left\langle T_{k}^{1}, T_{k}^{2}\right\rangle: k \in\{1,2,3,4\}\right\}=\{\langle 8,180\rangle,\langle 181,365\rangle,\langle 366,1825\rangle$,

$\langle 1826,1826+\rangle\}$.

3. Define set $I$ of all transactions, from which a sample is drawn. The sample is built from $k$ subsamples $I_{k}^{B}$ stratified by maturity. The minimum number of observations in the subsample is set at $m=10$. Denote the age of the 10-th transaction by $a_{10 k}$ in each subsample $k$. The subsamples are formed as follows:

- if on the day of the curve there were more than $m$ trades in maturity interval $k$, then subsample $k$ is defined as all transactions in maturity interval $k$ on that day:

$$
I_{k}^{B}=\left\{i \in I: a_{i}=1, T_{k}^{1}<t<T_{k}^{2}\right\}
$$

- otherwise, the subsample $k$ is defined as $m$ most recent transaction:

$$
I_{k}^{B}=\left\{i \in I: a_{i} \leq a_{m k}, T_{k}^{1}<t<T_{k}^{2}\right\} .
$$

4. The entire sample is $I^{B}=\bigcup_{k} I_{k}^{B}$.

5. Weighing occurs according to the following scheme:

$$
\forall i \in I_{k}^{B}: w_{i}=\frac{1}{k} \frac{\ln q_{i} * 10^{-a_{i} / \widehat{a}}}{\sum_{i=0}^{k} \ln q_{i} * 10^{-a_{i} / \widehat{a}}},
$$


where $q_{i}$ - volume of the transaction $i$;

$\hat{a}_{i}$ - age of transaction $i$,

$\hat{a}$ - age of the earliest transaction in the sample $I^{B}$.

6. Solution of the problem (8):

$$
\hat{b}=\arg \min _{b} \sum_{i}\left(y(i, b)-y_{i}\right)^{2} * w_{i} .
$$

Here $y_{i}$ is an actual yield to maturity for transaction $i$, thus corresponding to observed dirty price $p_{i}$, and $Y(i, b)$ is fitted yield to maturity for transaction $i$ (according to the model). In this program, parameters $b=\left(\beta_{0}, \beta_{1}, \beta_{2}, \tau\right)$ are chosen so as to minimise the weighted sum of squared deviations of the model yield to maturity from the actual.

The actual yield to maturity $y_{i}$ is the observed dirty price $p(i, b)$ that solves the following with respect to $y$ :

$$
p(i, b)=\sum_{j} e^{-y t_{i j}} c_{i j}
$$

The yield to maturity of transaction i according to the model $p(i, b)$ is calculated at each iteration of the algorithm, depending on the current $b$. For a given $b$, the element $i$ of this vector solves the following equation with respect to $y$ :

$$
p(i, b)=\sum_{j} d\left(b, t_{i j}\right) c_{i j},
$$

that is equal to the present value of cash flows from the security $c_{i j}$, discounted by rates, according to the model $b$, on corresponding terms of the flows $t_{i j}$.

7. The calculation of the zero-coupon and forward curves depending on the term $t$ is made for the parameters found using formula (5) and (6).

8. The calculation of the par yield curve, according to the definition (4), by numerical integration:

$$
w(t)=\frac{1-d(t)}{\int_{0}^{t} d(s) d s}=\frac{1-\exp (-t \cdot z(t))}{\int_{0}^{t} \exp (-s \cdot z(s)) d s} .
$$

9. According to the results of the evaluation of the model parameters, the following data set is published:

a) Spot-rate $z(t)$, momentary forward rate $f(t)$ and par yield $w(t)$ for a range of $t$ values;

b) Model parameters $\hat{\beta}=\left(\hat{\beta}_{0}, \hat{\beta}_{1}, \hat{\beta}_{2}, \hat{\tau}\right)$;

c)Age of the oldest transaction in the sample - $\hat{a}$, the age of the earliest transaction and the average age of transaction in each maturity interval $\left(\widehat{a_{1}}, \widehat{a_{2}}, \widehat{a_{3}}, \widehat{a_{4}}\right)$ and $\left(\overline{a_{1}}, \overline{a_{2}}, \overline{a_{3}}, \overline{a_{4}}\right)$;

d) Price and yield to maturity for outstanding securities calculated using formulas (10) and (9). 